\title{
Case report: \\ Ovarian cavernous hemangioma in two years old female with repeated UTI ; a case report and literature review
}

\author{
Zaid S. Khudher*, Ammar Abdulsalaam Hamid** \\ *Department of Surgery, College of Medicine, University of Mosul, \\ **Cardiovasculer Surgeon, Aljumhouri Teaching Hospital, Moaul.
}

(Ann. Coll. Med. Mosul 2011; 37 (1 \& 2): 135-137).

Received: $29^{\text {th }}$ Jun 2010; Accepted: $5^{\text {th }}$ Jun 2011.

\begin{abstract}
A two years old female child with history of a trivial trauma to the lower abdomen was complaining from repeated UTI.

Ultrasound and MRI examination of the abdomen and pelvis revealed $48 \times 30 \mathrm{~mm}$ solid pelvic mass. Excision of the mass was done through laparotomy. Histopathological examination revealed ovarian cavernous hemangioma.
\end{abstract}

الخلاصة

سجلت حالة نادرة لطفلة بعمر سنتين تشكو من التهاب المسالك البولية المتكرر. أظهر السونار وجود عقدة فى منطقة

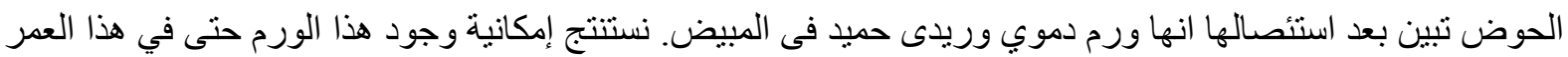
المبكر لذا ننصح بان تدرج في قائمة التشخيص التفريقي لأورام المبيض.

A Ithough the ovary itself is a highly vascularized organ hemangioma of the ovary is a very rare lesion ${ }^{(1)}$. Such benign tumours of the blood vessels are rare in ovaries during childhood ${ }^{(2)}$. The first case was reported by Payne in 1869 Although often an incidental finding at operation, ovarian hemangioma may rarely be associated with gynecologic cancers. ${ }^{(3)}$

\section{Case repot}

A two years old female patient presented with repeated attacks of urinary tract infections as frequency, difficulty in micturition over 1 year duration. History of a trivial trauma to the lower abdomen also reported

Clinically there was no significant finding elicited neither on general nor on abdominal examination.
General urine examination was repeated three times during the period of complaint and revealed pus cells and bacteria. The last was two weeks before surgery.

Urine culture and sensitivity revealed $\mathrm{E}$. coli sensitive to gentamicin, cephalexin, ceftriaxone and ciprofloxacin. Appropriate antibiotic was prescribed according to the result during attacks with good clinical response.

A retro-vesical solid mass measuring $48 \times 30$ $\mathrm{mm}$ was discovered by ultrasound examination of the abdomen and pelvis pressing on the urinary bladder, otherwise normal both kidneys. Same lesion in the retrovesical region causing pressure on the bladder was confirmed by MRI examination of abdomen and pelvis (fig.1).

Chest $\mathrm{x}$-ray and plane abdominal radiograph were normal. 
Through lower midline incision an exploratory laparotomy revealed a hemorrhagic mass at the left ovary, oophorectomy was done and sent for histopathology. (fig. 2)

The post operative period was uneventful (fig. 3). Histopathological examination revealed ovarian cavernous hemangioma.

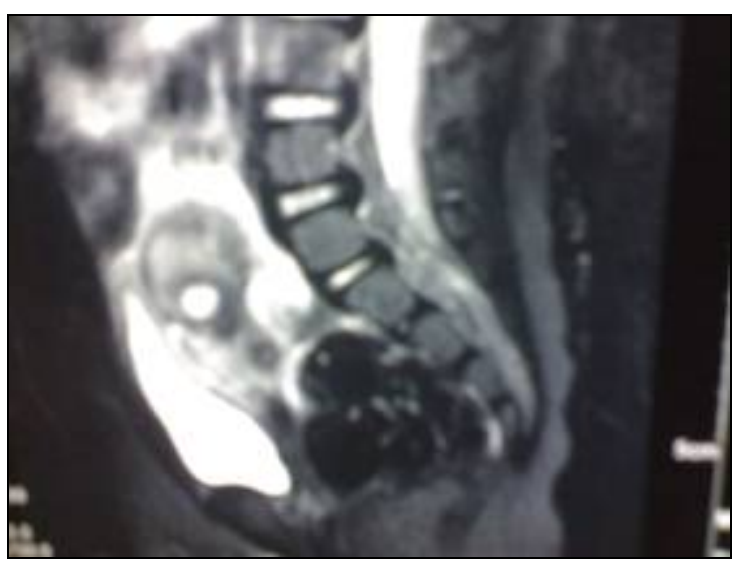

Figure (1)

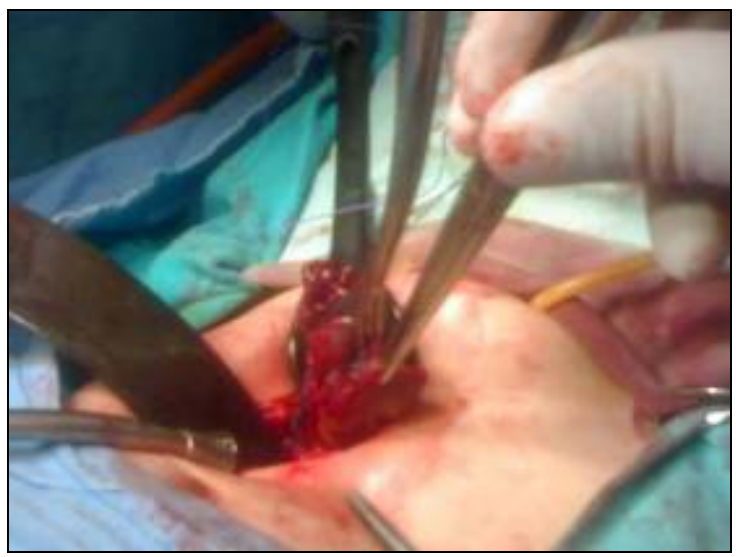

Figure (2)

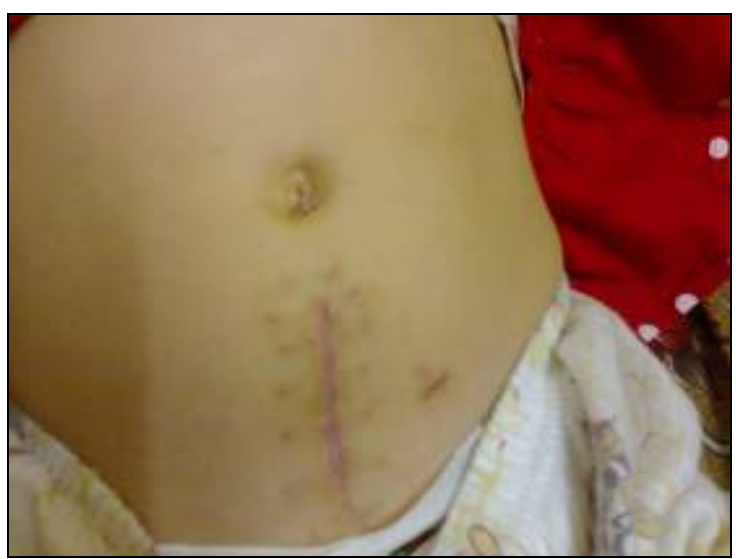

Figure (3)

\section{Discussion}

Vascular tumors of the female genital tract are rare especially those of the ovary. Alvarez and Cerezo $^{(4)}$ reported a case of cavernous hemangioma in 68 years old lady, unlike what was reported in this paper.

Extensive punctuate calcification in cavernous hemangioma was reported by Kim et $\mathrm{al}^{(5)}$; the present tumor was devoid of calcification probably because of early presentation and surgery.

Vague abdominal and pelvic pain were the presenting features in an 11 and 32 years old patients reported by Correa-Rivas et al ${ }^{(6)}$ and Cormio et al ${ }^{(7)}$ respectively. The second was due to a big pelvic tumor, while repeated (UTI which may be coincidental or due to pressure effect of the mass) was the leading feature at the time of presentation in our case. Akbulut et $\mathrm{al}^{(3)}$ reported coexistence of the hemangioma with a serous papillary carcinoma of the ovary and an endometrial polyp in a 65 years old woman unlike our case which was a child and no such an association.

Disseminated vascular tumors involving both ovaries, both lungs and pleura, pericardium, and mediastinum was reported by Miyauchi et al ${ }^{(8)}$.

\section{Conclusion}

Despite the rarity of this tumor, it is advised to be taken into consideration in the differential diagnosis of ovarian tumors.

Recurrent UTI is one way of presentation in children, in addition to pressure symptoms and vague pelvic or abdominal pain in adults.

\section{References}

1. Sohn JH, Park YE, Lee YW. Cavernous Hemangioma of the Ovary. Korean $\mathrm{J}$ Pathology. 1996 Jun; 30(6):554-6.

2. M'pemba Loufoua-Lemay $A B$, Peko JF, Mbongo JA, et al. Ovarian torsion revealing an ovarian cavernous hemangioma in a child. Arch pediatr. 2003 Nov;10(11):986-8.[article in French]

3. Akbulut $\mathrm{M}$, Bir $\mathrm{F}$, Colakoglu $\mathrm{N}$, et al. Ovarian hemangioma occurring synchronously with serous papillary carcinoma of the ovary and benign 
endometrial polyp. Annals of Saudi Medicine 2008; 28(2):128-32.

4. Alvarez M, Cerezo L. Ovarian cavernous hemangioma. Arch Pathol Lab Med. 1986 Jan; 110(1):77-8.

5. KIM M Y, RHA S E, OH S N, et al. Ovarian cavernous hemangioma presenting as a heavily calcified adnexal mass. British Journal of Radiology 2008; 81: 269-271.

6. Correa-Rivas MS, Colon-Gonzales G, Lugo-Vicente $\mathrm{H}$. Cavernous hemangioma presenting as a right adnexal mass in a child. P R Health Sci J. 2003 Sep; 22(3): 311-3.
7. Cormio G, Loverro $\mathrm{G}$, lacobellis $\mathrm{M}$, et al. Hemangioma of the Ovary: A case report. The journal of Reproductive Medicine 1998;43:459-61.

8. Miyauchi J, Mukai M, Yamazaki $\mathrm{K}$ et al. Bilateral ovarian hemangiomas associated with diffuse hemangioendotheliomatosis: a case report. Acta Pathol Jpn. 1987 Aug; 37(8): 1347-55. 